\title{
LABOR MINERA Y PROTECCIÓN DEL MEDIO AMBIENTE: CRITERIOS PARA UNA REDEFINICIÓN*
}

\author{
JORGE RETAMAL VALENZUELA**
}

RESUMEN: El presente ensayo, luego de mostrar diversas opiniones, propone una definición del concepto de labor minera que se encuentre asociado a su ejecución en áreas sometidas a protección oficial. Salvo un pronunciamiento expreso del Ministerio de Minería, no existe claridad en cuanto a qué debe entenderse por aquellas labores en nuestra legislación. La Jurisprudencia solo ha esbozado algunas ideas, sobre el sentido y alcance de este concepto. De este modo, es un tema que no se ha zanjado en el ordenamiento jurídico.

Al no estar definido el concepto de labor minera, la normativa no es específica para dilucidarlo, y hace colisionar las facultades de dominio del concesionario minero, reguladas en disposiciones sectoriales, con el deber del Estado de proteger la naturaleza y conservar el patrimonio ambiental, igualmente establecido en nuestra Constitución. Este virtual conflicto debe ser solucionado por el ordenamiento jurídico para no destruir innecesariamente estos lugares sensibles.

PALABRAS CLAVE: Labor Minera - Áreas Silvestres - Minería - Ambiental - Concesiones

\section{MINING WORK AND ENVIRONMENTAL PROTECTION: CRITERIA FOR REDEFINING}

ABSTRACT: This paper after displaying various views, proposes a definition of mining work that is associated with its implementation in areas under official protection. Unless an express statement of the Ministry of Mines of Chile, there is no light as to what is meant by those tasks in our legislation. The Courts have only outlined some ideas about the meaning

Fecha de recepción: 1 de agosto de 2014.

Fecha de aceptación: 4 de febrero de 2015.

** Abogado. Licenciado en ciencias jurídicas por la Universidad Católica del Norte (ChIle). Magíster (c) en Derecho Ambiental, Universidad de Chile (Chile). Ministro Titular Abogado del Ilustre Tercer Tribunal Ambiental de Chile. Correo electrónico: jorge.retamal.rv@ tercertribunalambiental.cl 
and scope of this concept. Thus, it is an issue that has not been settled in the legal system.

Not being defined the concept of mining work, the legislation is not specific to consolidate faculties domain mining concessionaire regulated by sectoral rules, the State's duty is to protect nature and conserve the environmental heritage, also established in our Constitution. This virtual conflict must be solved by law not to destroy those sensitive sites unnecessarily.

KEY WORDS: Mining work - Wilderness Areas - Mining - Environmental - Concessions

Sumario. Introducción. 1. Algunas aproximaciones conceptuales. 1.1. Un acercamiento al concepto, por exclusión. 1.2. Pronunciamiento del Ministerio de Minería. 1.3. ¿Y qué dicen la Doctrina y la Jurisprudencia? 1.4. Al final del dia. 2. Una visión integradora y global. 3. Indefensión de las Áreas Silvestres Protegidas. 4. Noción amplia del concepto y fines de conservación perseguidos por el Estado. Su relación con la nueva institucionalidad ambiental. 4.1. ¿Definición legal o jurisprudencial? 5. Una propuesta de definición. 5.1 Cuando se ejecuten en áreas sometidas bajo protección oficial. 5.2. Toda actividad que se realice en un territorio 5.3. Que su objeto sea la preparación y el desarrollo de actividades mineras. 5.4. Que no haya sido definida como faena minera por las leyes o reglamentos. 6. Consecuencias de esta definición. Conclusiones.

\section{INTRODUCCIÓN}

Como se verá en el desarrollo de este ensayo, la definición del concepto de Labor Minera no es pacífica, ni en la doctrina ni en la jurisprudencia, judicial o administrativa; básicamente porque no ha habido acuerdo en delimitar la extensión de las facultades de catar y cavar y otras actividades similares, cuando estas se llevan a cabo en territorios ajenos a los del titular de una concesión minera.

Ello genera el siguiente problema: Cada vez que un titular de una concesión minera, sea de exploración o explotación, desea ejercer su legítimo derecho de delimitar la superficie afecta a ella, tiene el derecho absoluto para llevarla a cabo, debiendo indemnizar a los propietarios del terreno y pagar las servidumbres que de común acuerdo o la justicia en subsidio así lo determinen. No obstante, ello no le impedirá nunca ingresar a los terrenos, si cuenta con las autorizaciones del dueño del terreno o la justicia en subsidio.

Esta situación, que se encuentra amparada por nuestro ordenamiento jurídico, pone en peligro la integridad de aquellos lugares que se 
encuentran sometidos bajo protección oficial ${ }^{1}$, sobre los cuales pueden válidamente llevarse a cabo estas actividades sin mayor obligación para el concesionario, que pedir las autorizaciones legales e indemnizar a los dueños del terreno, cuando ello sea procedente. Nada se dice en cuanto a conservar la intangibilidad de los territorios, ni de la inalterabilidad de los hábitats que el Estado ha determinado proteger, en concordancia con nuestra Constitución y los tratados internacionales que Chile ha suscrito sobre la materia.

Existen muchas de estas actividades que están al límite de la definición de labor minera -en su sentido y alcance sectorial que se analizará-y que, al no ser propiamente acción y efecto de excavar quedarían fuera, es decir, no estarían sujetas a ningún tipo de autorización previa para ejercerse. Estas actividades limítrofes revisten un peligro para los ecosistemas sensibles protegidos, cada vez que sobre ellos se haya constituido una concesión minera, como ocurre en varias de las áreas silvestres protegidas del Estado existentes en las regiones de Arica-Parinacota, Tarapacá y Antofagasta, por mencionar algunos casos ${ }^{2}$. En estos lugares, por ejemplo, no existe una herramienta legal que impida que se lleven a cabo tareas de prospección, o incluso de demarcación de puntos medios o puntos de interés usando monolitos en dichas áreas; debido a que en la situación actual no pueden definirse propiamente como labores mineras, al no ser propiamente actividades de cavar o excavar ni estar definidas así en nuestra legislación. Las consecuencias de ello, en sitios que son valiosos por su belleza escénica o inalterabilidad de sus ecosistemas, pueden llegar a ser irreparables.

Como consecuencia de ello, luego de que se analice la interpretación del Ministerio de Minería, el lector apreciará cómo se pone en riesgo la conservación de las áreas sometidas bajo protección oficial, ante la ejecución de actividades de aparente bajo impacto en estos lugares -si son individualmente consideradas entre sí- pero que son susceptibles de generar efectos adversos de aquellos definidos en la ley ${ }^{3}$. Dejar a estas actividades fuera de la esfera de protección legal y reglamentaria, lleva consigo el riesgo de que, producto de ellas, se pueda generar un impacto mayor, cuando se lleven a cabo en un Área Silvestre Protegida o dentro de sus proximidades.

El tema en comento cobra importancia, cuando estas labores o actividades se van a llevar a cabo en terrenos donde el catar y cavar se encuentra regulado o prohibido, como ocurre en terrenos privados o en

De aquellos a que se hace referencia en el artículo 10, letra p) y 11 letra d) de la Ley $\mathrm{N}^{\circ}$ 19.300 .

2 Así sucede, por ejemplo, en la Reserva Nacional Los Flamencos, el Monumento Natural Salar de Surire y la Reserva Nacional Pampa del Tamarugal, que son áreas silvestres protegidas ubicadas en el Norte de nuestro país.

3 Me refiero acá al artículo 11 de la ley 19.300, sobre Bases Generales del Medio Ambiente. 
áreas silvestres protegidas. En tales circunstancias, y dependiendo de las características propias del lugar, la autorización la dará el dueño del terreno, o las autoridades regionales o nacionales, según el caso de que se trate. Esta problemática, salvo fallos puntuales de los Tribunales Superiores, no se ha resuelto hasta el día de hoy.

En las siguientes páginas, se expondrá el actual conflicto existente entre la legislación sectorial -en este caso la legislación minera- y las normas ambientales, y cómo los bienes jurídicos protegidos sectorialmente se superponen -como ya he señalado dos párrafos más atrás-; denotando la necesidad de legislar para definir expresamente el concepto de labor minera, en su dimensión amplia, que compatibilice las facultades que la ley confiere al dueño de una concesión minera, por una parte, con la protección del medio ambiente y la conservación de la naturaleza, por la otra. Como se verá, esta compatibilización de intereses es posible en virtud de la ubicuidad de que goza el Derecho Ambiental, así como de la aplicación del Principio Preventivo, propio de esta última rama del Derecho.

\section{1) AlgunAS APROXIMACIONES CONCEPTUALES}

El concepto de Labor Minera se encuentra mencionado en diversos pasajes del Código de Minería y en algunas de sus normas complementarias. Así, y en cuanto al Código de Minería, podemos encontrar este concepto en los artículos 127, 139 y 140, sin que en ellos exista una definición expresa y precisa de qué se entiende por tales labores ${ }^{4}$. Ninguno de estos pasajes del Código lo define claramente, impidiendo su real precisión. Por otra parte, en el Reglamento de Seguridad Minera, nuevamente se menciona el concepto de labores mineras, sin definirlas claramente, como ocurre en su artículo $79^{5}$. No obstante $-\mathrm{y}$ en este sentido huelga

"Articulo 127.- Las concesiones mineras están especialmente sujetas a la servidumbre de ser atravesadas por labores mineras, destinadas a dar o facilitar ventilación, desagüe o acceso a otras concesiones mineras o a un establecimiento de beneficio..."

"Artículo 139. - Se prohibe al minero internarse con sus labores en concesión ajena..."

"Articulo 140.- El minero que sospeche internación o que tema inundación o derrumbe, por el mal estado de las labores de la concesión contigua o próxima o por el desarrollo de los trabajos que en ella se efectúan, tendrá derecho a visitarla, asesorado por un perito".

5 "Artículo 79: En toda mina en explotación deberán existir, a lo menos, dos labores principales de comunicación con la superficie, ya sean piques, chiflones o socavones, de manera que la interrupción de una de ellas no afecte el tránsito expedito por la otra. Las labores en servicio activo de la mina deberán, a su vez, tener una comunicación expedita con las labores principales de comunicación a la superficie, las que se mantendrán siempre en buen estado de conservación y salubridad.

Las referidas labores principales de comunicación con la superficie, deberán tener los elementos necesarios para la fácil circulación de las personas, en tal forma que, en caso de emergencia, éstas no tengan necesidad de adaptar equipos especiales de izamiento o de movilización para salir a la superficie". 
ser objetivo- los pasajes legales y reglamentarios antes expuestos apuntan claramente a la ejecución de actividades subterráneas, vinculadas a excavaciones de túneles o ductos.

\section{1) UN ACERCAMIENTO AL CONCEPTO, POR EXCLUSIÓN}

En la ley $\mathrm{N}^{\circ} 20.551$, sobre cierre de faenas e instalaciones mineras, el legislador se aproximó al concepto por vía de exclusión. A propósito de sus definiciones, indica qué debe entenderse por Faenas o instalaciones mineras, señalando que son "El conjunto de instalaciones y lugares de trabajo de la industria minera..." 6 y luego, en un prolongado "tales como..." se extiende en un catálogo de instalaciones y equipamientos -en los cuales ya queda claro que ninguno de los mencionados podría ser catalogado como labor minera- para terminar con el siguiente corolario:

"... y en general, la totalidad de las labores, instalaciones y servicios de apoyo e infraestructura que existen respecto a una mina o establecimiento de beneficio para asegurar el funcionamiento de las operaciones mineras".

Guiarse por esta línea interpretativa permite despejar, a contrariu sensu, qué cosas no deben ser consideradas labores mineras, despejando en algo la duda acerca de qué debe entenderse por ellas.

\section{2) Pronunciamiento del Ministerio de Minería}

Uno de los pronunciamientos que se han referido en forma específica a la materia, fue hecho por el Ministerio de Minería, y se encuentra contenido en el Oficio INT. DIV. JUR. N ${ }^{\circ} 20.574$, de 26 de septiembre de 2012, en que responde una consulta efectuada por el Servicio de Evaluación Ambiental, hecha mediante OF. ORD. D.E. $\mathrm{N}^{\circ}$ 121.587, de 30

Ley $\mathrm{N}^{\circ} 20.551$, artículo $3^{\circ}$, letra i).

Ley $\mathrm{N}^{\circ} 20.551$, artículo $3^{\circ}$, letra i). El texto completo del esta letra "i)" es el siguiente: “...i) Faena minera e industria extractiva minera: Se entenderá por Faena Minera el conjunto de instalaciones y lugares de trabajo de la industria extractiva minera, tales como minas, plantas de tratamiento, fundiciones, baterias, equipamiento, ductos, oleoductos y gasoductos de hidrocarburos, maestranzas, talleres, casas de fuerza, puertos de embarque de productos mineros, campamentos, bodegas, lugares de acopios, pilas de lixiviación, depósitos de residuos masivos mineros, depósitos de relaves, de estériles, ripios de lixiviación y, en general, la totalidad de las labores, instalaciones y servicios de apoyo e infraestructura que existen respecto a una mina o establecimiento de beneficio para asegurar el funcionamiento de las operaciones mineras.

Para los efectos de esta ley se considerará industria extractiva minera el conjunto de actividades relacionadas con la exploración, prospección, extracción, explotación, procesamiento, transporte, acopio, transformación, disposición de sustancias minerales, sus productos y subproductos; las sustancias fósiles y depósitos de hidrocarburos líquidos o gaseosos, en las condiciones específicas que se señalan en el Titulo XII. La industria extractiva minera incluirá el conjunto de obras destinadas a abrir, habilitar, desarrollar, instalar y adosar permanentemente, en su caso, las excavaciones, construcciones, túneles, obras civiles y maquinarias que tengan estrecha relación con las actividades antes señaladas". 
de agosto de 2012. En este documento, toma posiciones en cuanto a la amplitud o restricción del concepto Labor Minera para efectos de los permisos ambientales sectoriales del reglamento del SEIA ${ }^{8}$.

El Ministerio citado es categórico al señalar que la noción de labor minera es restringida, y debe remitirse a los trabajos mineros de exploración y excavación. Lo anterior, basado fundamentalmente en la definición expresa que la voz labor minera tiene en materias de esa índole. A propósito de ello, se hace cargo de las definiciones específicas existentes en determinados cuerpos legales o reglamentarios -se remite a los casos del artículo 593 del Reglamento de Seguridad Minera y la Ley de Cierre de Faenas Mineras-, señalando que tales definiciones no alteran el sentido original de un concepto que en la ley general ha dado, o ha fijado las vías por las que se puede interpretar dicho concepto, al estar definidos así para efectos de la aplicación de dichas leyes. Adicionalmente a ello -señala el Ministerio- el sentido natural y obvio de la expresión labores mineras tampoco -a su juicio- autoriza para darle la extensión o aplicación que se le da en la ley y reglamentos sobre la materia, máxime cuando en la minería y la legislación nacional pertinente está referido a la apertura de la tierra, o la excavación para la investigación, arranque y extracción de sustancias minerales. La misma idea -sostienen- se extrae de la acepción del término labor en la Real Academia Española.

Asimismo, su argumento se basa en una razón de geografía del texto del Código de Minería, y de lo dispuesto en Ley Orgánica Constitucional (LOC) sobre Concesiones Mineras. Sobre el primero de los cuerpos nombrados, sostiene que el artículo 17 del Código de Minería se encuentra situado en el párrafo primero, que se refiere a las facultades de catar y cavar, no debiendo privar al concepto de labor minera de tal sentido; porque el objeto de una concesión minera es cavar y excavar para explotar el mineral. Por otro lado, el artículo 591 del Código Civil se refiere a ello cuando habla de "labrar o laborear la mina", que no es otra cosa que sacar de la tierra. En cuanto a la LOC antedicha, indica el Ministerio que lo esencial de la facultad que se le concede al concesionario es arrancar y extraer los minerales, lo que se confirma en el sentido del artículo $7^{\circ}$ de la misma ley ${ }^{9}$.

Concluyen diciendo que una noción amplia del concepto es contrario a lo que señala el artículo $8^{\circ}$ de la ley de concesiones mineras, ya que las labores son, a su juicio, las que el concesionario efectúa "en" la pertenencia para extraer sustancias de las excavaciones.

Contenido en el Decreto Supremo No 40, de 2012, del Ministerio del Medio Ambiente. Señala el artículo, en lo pertinente, "Artículo $7^{\circ}$. Todo concesionario minero tiene la facultad exclusiva de catar y cavar en tierras de cualquier dominio con fines mineros dentro de los límites de la extensión territorial de su concesión". 


\section{3) ¿Y QUÉ DICEN LA DOCTRINA Y LA JURISPRUDENCIA?}

Cuando el legislador no ha establecido definiciones, lo que procede es aplicar las reglas generales de interpretación establecidas en los artículos 19 al 24 de nuestro Código Civil. Al no haber interpretación legal, el otro camino de interpretación que es relativamente vinculante -descartando solo desde ese punto de vista la interpretación por vía doctrinariaes la interpretación judicial, no obstante -en virtud del efecto relativo de las sentencias existente en el ordenamiento jurídico chileno-, no es vinculante absolutamente, al tener fuerza obligatoria solo respecto de las partes de las causas en que actualmente se pronunciaren ${ }^{10}$.

No obstante lo anterior, es necesario considerar la jurisprudencia como otra vía de interpretación útil en estos casos para dilucidar la encrucijada, a manera de seguir buscando la respuesta sobre qué debe entenderse por Labor Minera, luego de haber avanzado sobre ello en los párrafos que anteceden.

Sobre el tema, la jurisprudencia no ha sido muy profusa. La Corte Suprema se ha referido al menos en tres ocasiones a este concepto, también de manera tangencial, pero con opiniones más cercanas a precisar el concepto sobre el particular. Ello ha sucedido en las causas "MINERA RICARDO RESOURCES INC. CON CODELCO CHILE", y "ENRIQUE OVALLE BARROS, Inaplicabilidad por Inconstitucionalidad". En la primera de ellas, se aventura a indicar que dentro del concepto de labor minera no solo deben incorporarse las actividades estrechamente vinculadas con las facultades de catar y cavar, que define el Código de Minería, sino que además aquellas que le preceden y que permiten preparar su posterior ejecución. El primero de los fallos aludidos (Minera Ricardo Resources con CODELCO CHILE) indica en sus considerandos lo siguiente:

"... En efecto en aludido artículo 17, haciendo presente la expresión: sin perjuicio de los permisos de que trata el artículo 15 exige otros para ejecutar labores mineras, comprendiendo con esta frase, las faenas necesarias para catar y cavar y todas las demás que sean propias del derecho minero, como deben ser las de exploración y explotación y no se ve por qué debieran excluirse los trabajos u obras para constituir servidumbres mineras que necesariamente implican un trabajo o laboreo de naturaleza minera y propios dentro de los derechos de las concesiones de exploración y explotación..." 11.

\footnotetext{
10 Tal como lo señala el Código Civil, en su artículo $3^{\circ}$, inciso $2^{\circ}$.

11 Corte Suprema. 28 de junio de 2006. Rol No 2095-2004. "Minera Ricardo Resources Inc. S.A. con CODELCO Chile". Disponible en http://suprema.poderjudicial.cl/ SITSUPPORWEB/DownloadFile.do?TIP_Documento $=3 \&$ TIP_Archivo $=3 \&$ COD_ Opcion $=1 \&$ COD_Corte $=1 \&$ CRR_IdTramite $=255168 \&$ CRR_IdDocumento= 129573 [fecha de visita: 15 de mayo de 2014] p. 12.
} 
Esta interpretación, del máximo Tribunal de la República, es concordante con los fines de protección del patrimonio ambiental de nuestro país, alejándose -en cuanto a las actividades que se comprenden dentro de la idea de asimilarlo a excavaciones y túneles mineros-, de la aplicación restrictiva del concepto para ir más allá, en una idea más comprensiva del mismo, ampliando esta noción a aquellas actividades que sin ser de un mayor impacto - comparado con una excavación- pueden de todas maneras constituirse en impactos significativos cuando -pese a ser aparentemente inocuas- se efectúan dentro de un área silvestre protegida con la finalidad de proyectar una explotación o intervención posterior.

En el mismo sentido, en el recurso de inaplicabilidad por inconstitucionalidad del señor Enrique Ovalle Barros, la Corte Suprema se refiere al tema del modo siguiente:

"... se desprende que la Constitución trata en forma separada la facultad que tiene toda persona para catar y cavar en tierras de cualquier dominio (...) ... Ello se debe a que, ciertamente, son cosas diferentes en su origen $y$ finalidad. En efecto, la primera de ellas, la facultad que tiene cualquier persona de realizar aquellas labores..." 12 .

Indirectamente, en este fallo, vincula el concepto de labor con el de las facultades de catar y cavar. Es decir, amplía la noción originalmente planteada que por Labor Minera debe entenderse solamente las actividades extractivas propiamente tales, como túneles o ductos subterráneos o el movimiento de tierra necesario y propio de la explotación a rajo abierto; para agregar además, al concepto de labor minera a aquellas actividades propias del catar, que no es otra cosa que la búsqueda que se hace por el minero, tenga o no a su favor una concesión de exploración. Así, y poniéndonos en el caso de un titular de una concesión de exploración, incluso las actividades propias de la delimitación del área concedida quedarían comprendidas en el concepto cuya definición se requiere, lo que acarrea importantes consecuencias ambientales.

La indefensión en que se encuentran las áreas silvestres protegidas en nuestra legislación, frente a los derechos del titular de una concesión minera, queda más claramente demostrada a nivel jurisprudencial. Así ha sucedido en casos en que se ha recurrido en contra de alguno de los entes que administran estas áreas cuando no han permitido el ingreso a ella para efectuar labores que, sin ser propiamente labores mineras conforme a la normativa actual, han sido proyectadas para servir de base a la ejecución de futuros proyectos de carácter extractivo.

En los autos sobre recurso de protección caratulados "COMPAÑíA MINERA BARRICK CHILE LIMITADA con CORPORACIÓN NA-

12 Corte Suprema. 28 de noviembre de 1997. Rol N²1.230-1993. "Monte Patria 1 al 6". Gaceta Jurídica, No 209, pp. 84-88. 
CIONAL FORESTAL"13, cuyo fallo fue confirmado en forma unánime por la Excma. Corte Suprema, trata precisamente el conflicto que motiva este ensayo, con ocasión de la dictación de la resolución exenta $\mathrm{N}^{\circ}$ 174, de 10 de noviembre de 2004, de CONAF, que negó el ingreso a la recurrente al Parque Nacional Volcán Isluga. En dicha oportunidad, la Compañía Minera Barrick Chile Limitada había solicitado a CONAF ingresar al parque nacional referido, para efectuar las tareas necesarias que fueran conducentes a la elaboración de una línea de base necesaria para el Estudio de Impacto Ambiental que debía ser presentado a las autoridades regionales, para realizar trabajos de exploración mineras. En los considerandos $7^{\circ}, 8^{\circ}, 9^{\circ}$ y $11^{\circ}$ del fallo aludido, que acoge el recurso interpuesto, la Iltma. Corte de Apelaciones de Arica sustenta su decisión, entre otras razones, en lo siguiente:

"...el ingreso al Parque Nacional Volcán Isluga para el efecto de efectuar un levantamiento de información tendiente a la elaboración de una linea de base, o fotografia del lugar, y sus condiciones ambientales (...) no importa ciertamente ejecutar labores mineras en dicho parque (...) en los términos referidos en los artículos 113, 114 y 116 del Código de Minería..."14.

Es decir, al no ser las tareas solicitadas labores mineras a la luz de la legislación, ni asemejarse las mismas a las actividades de catar y cavar, se entiende que no regirían para tales casos los requisitos de autorizaciones especiales que regula el artículo 17 del Código de Minería, en este caso la de su número 2, por lo que resolvió acoger el recurso de protección interpuesto y ordenar a la Corporación Nacional Forestal que autorizara el ingreso a la recurrente para llevar a cabo las tareas solicitadas.

En cuanto a la doctrina, autores como Alejandro Vergara Blanco, a propósito de la mensura, es de la opinión de que dicha operación y todas las actividades relacionadas con ella no deben ser consideradas labores mineras, ya que "...tal trabajo de campo no es "labor minera", sino solo una medición de terreno..." 15 .

\section{4) AL FINAL DEL día}

Sin restarle el valor a la opinión de un órgano de la administración del Estado, emitida en alguno de sus oficios, o a la opinión de autores que

13 Corte de Apelaciones de Arica. 31 de diciembre de 2004. Rol N 624-2004. “Compañía Minera Barrick Chile Limitada con Corporación Nacional Forestal”.

14 Corte de Apelaciones de Arica. 31 de diciembre de 2004. Rol No 624-2004. "Compañía Minera Barrick Chile Limitada con Corporación Nacional Forestal”. Considerando $7^{\circ}$.

15 Vergara Blanco, Alejandro (1992) "Constitucionalidad de la facultad de catar y cavar en suelo ajeno por quien no es aún concesionario minero". Revista de Derecho de Minas y Aguas. Volumen III. Pp. 193-196. Disponible en: http://vergarablanco.cl/Publicaciones/VI.\%20 Derecho\%20de\%20Mineria/AVB\%20VI\%2025\%201992\%20MINERIA\%20constitucionalidad\%20catar\%20cavar.PDF [Fecha de visita 15 de mayo de 2014]. 
han escrito sobre la materia, lo señalado debe ser considerado un aporte más al debate de ideas; y constituye una muestra clara de la necesidad de zanjar el tema, de un modo más definitivo, por la vía legal.

En este mismo sentido, fallos como el de la causa "COMPAÑíA MINERA BARRICK CHILE LIMITADA con CORPORACIÓN NACIONAL FORESTAL" muestran, de manera clara, la necesidad de revisar la regulación existente sobre el particular, precisamente porque en esta materia no se ha legislado poniendo especial preocupación en las áreas protegidas.

Por su parte, la Jurisprudencia, en ocasiones como la referida, ha entendido que la sola actividad tendiente a la elaboración de una línea de base -por ejemplo- no puede ser considerada para estos efectos labores mineras, ya que la ley no lo considera así; de manera que no existiendo óbice debe darse la autorización para ello, aun sabiendo que dicha tarea es el punto de partida para una serie de actividades que derivarán en trabajos extractivos. La indefensión que la ausencia de regulación específica de ello es lo que hace nacer la necesidad de llevar a cabo una innovación legal como la que en este ensayo se propone.

\section{2) UNA VISIÓN INTEGRADORA Y GLOBAL}

Si bien la aplicación restringida del concepto pudiera considerarse la apropiada desde el punto de vista netamente sectorial extractivo, no es menos cierto que una mirada holística del ordenamiento jurídico hace forzoso analizar el concepto desde un punto de vista más amplio, incorporando en esta nueva mirada los principios propios del Derecho Ambiental. Cuando la afectación, producto de las actividades vinculadas a la minería, impacta en un área silvestre protegida, entonces la problemática debe incorporar en su solución los principios propios de esta última rama del Derecho.

La minería tiene una estrecha y obvia relación con el medio ambiente, que es donde impactan sus actividades. Asimismo, el Derecho Minero debe estar en consonancia con los principios del Derecho Ambiental, máxime cuando se trata de regular las actividades que se planee desarrollar en las áreas y lugares sujetos bajo protección oficial; toda vez que estos lugares - por su extrema sensibilidad- son la manifestación más clara del deber de cuidado del medio ambiente y el objeto per se de la protección del entorno como reserva de la biosfera, o como belleza escénica, que se transforma en uno de los principales bienes jurídicos protegidos por esta normativa. Esta sola circunstancia, obliga al intérprete a ampliar el campo de aplicación de la noción en comento, al ser más amplio el ámbito de afectación de dichas actividades, e impone el deber de interpretar la legislación en estos casos con un sentido amplio que abarque y concilie todos los bienes jurídicos protegidos que se encuentran en conflicto. 
Cuando la exploración o la explotación se pretenda realizar en un área silvestre protegida o en sus inmediaciones más cercanas, no solamente se va a intervenir un terreno determinado, sino que además se afectará el entorno, el medio ambiente, en una zona que además es sensible, tanto así que se encuentra bajo protección oficial.

Este solo cambio de perspectiva amplía el espectro, y obliga a incluir, en esta definición, criterios más acordes con la protección del medio ambiente, escapando del plano meramente productivo-extractivo. Así, no se provocará la indefensión de estos lugares frente a la ejecución de actividades tales como, por ejemplo, la demarcación de una pertenencia minera o la sola exploración del territorio mientras se catea.

Estas últimas actividades van a tener un mayor impacto en áreas sensibles, y por eso también debieran ser autorizadas previamente, ya sea por vía de una declaración de pertinencia de ingreso al SEIA, o mediante una autorización sectorial, de aquellas contenidas en el artículo $7^{\circ}$ del Código de Minería y que sea aplicable.

La lectura de los párrafos anteriores, muestra la forma en que colisionan la legislación minera y el mandato constitucional de tutelar la conservación de la naturaleza ${ }^{16}$, mandato que se ha materializado en nuestro país con la creación de más de 100 áreas silvestres protegidas a lo largo de nuestro territorio, lo que además es conteste con los compromisos suscritos por el Estado de Chile sobre la materia, vigentes en nuestro país como Ley de la República ${ }^{17}$.

Entonces, la pregunta es, ¿cómo compatibilizamos las facultades del concesionario minero, con los principios y las disposiciones de nuestra institucionalidad ambiental? Es decir, tenemos que encontrar la manera en que puedan convivir, pacíficamente, los intereses amparados en el régimen jurídico del concesionario minero -constitucional y legalmente establecido- con el deber igualmente importante del Estado, manifestado en el 19 número 8 de nuestra Constitución -como ya se indicó- de vivir en un medio ambiente libre de contaminación, deber que legitima el interés de la comunidad de conservar inalterable el patrimonio ambiental y la intangibilidad de la belleza y el equilibrio de estos lugares que con tal propósito son áreas silvestres protegidas. A mayor abundamiento, se trata de buscar la manera de conciliar esos mismos intereses productivos mineros con los principios emanados del Derecho Internacional del Medio Ambiente, ma-

16 Mandato que se encuentra consagrado en el artículo 19 , número $8^{\circ}$, de nuestra Constitución Política. (Nota del autor).

$17 \mathrm{Al}$ respecto, podemos solo mencionar la Convención de Washington para la protección de la flora, la fauna y las bellezas escénicas naturales de América, la Convención de Río de Janeiro sobre Biodiversidad, la Convención de Bonn sobre especies migratorias, la Convención de Ramsar sobre protección de humedales de importancia internacional, el Convenio $\mathrm{N}^{\circ} 169$, de la O.I.T. sobre pueblos indígenas y tribales en países independientes; entre otros instrumentos internacionales. 
nifestados en los diversos tratados suscritos sobre la materia por Chile y que actualmente son vigentes en el país como Ley de la República.

Una primera mirada nos lleva a decir que la mera interpretación sectorial descrita en párrafos anteriores no es suficiente para abarcar el problema, sino que se resuelve integrando los principios del Derecho Ambiental, aplicando la ley con una nueva mirada para resolver esta clase de conflictos. Así, veremos cómo actividades aparentemente inocuas, de las cuales ya nos hemos referido suficientemente, deben ser consideradas labores mineras, y someterse al régimen de permisos que ha dispuesto el legislador para ello, para que no provoquen daños irreparables en los lugares bajo protección oficial. En otras palabras, la evolución del Derecho nos lleva a la integración de todas sus ramas y dejar de lado la visión sectorial de los casos concretos en que haya que aplicarse la ley. El mismo criterio debe emplearse al momento de interpretarla, ampliando el foco de acción. En este sentido, el autor Ramón Martín Mateo ha planteado, a propósito del principio de Ubicuidad del Derecho Ambiental que "... Prácticamente todas las autoridades públicas encuentran sus competencias implicadas en la defensa del medio, lo que ha hecho inevitable el adaptar estrategias que sustituyan el enfoque sectorial y vertical precedente, por el general y horizontal que hoy es inevitablemente dominante. Todo esto no cabe en un artículo de la Constitución ni casa con los presupuestos clásicos del constitucionalismo, es otro enfoque que no estamos por cierto en condiciones de recibir..."18. Es esta visión global la que debe asumir el intérprete para apreciar el escenario y las consecuencias que una interpretación restrictiva del concepto de labor minera puede producir si actividades como las descritas en párrafos anteriores no son sometidas al control de la autoridad y caen dentro de las facultades absolutas del cateador.

A la misma conclusión es posible llegar por aplicación del Principio Preventivo del Derecho Ambiental, el cual se encuentra incorporado en nuestra legislación en el artículo 19, número $8^{\circ}$ de la Carta Fundamental (“...Es deber del Estado (...) tutelar la preservación de la naturaleza...") y en el mensaje de la ley $\mathrm{N}^{\circ} 19.300$, cuando señala, a propósito de este principio que "... mediante este principio, se pretende evitar que se produzcan los problemas ambientales..."19. En el mismo tenor sostiene el autor Rodrigo GuZMán Rosen cuando señala que “... Con este principio se desea señalar que en materia ambiental resulta esencial actuar de modo de aminorar o suprimir los efectos ambientales que pudieren derivarse de la actividad humana, incorporando medidas que vayan en tal sentido antes de ejecutar

19 Congreso Nacional (1994). Historia de la Ley No 19.300 Bases del Medio Ambiente. Valparaíso: 1226 pp. Disponible en: http://www.leychile.cl/Consulta/portada_hl?tipo_ norma $=X X 1 \&$ nro_ley=19.300\&anio=2014. [fecha de visita 14 de mayo de 2014], p. 14 . 
una determinada acción que se supone alteradora del medio en términos relevantes..." 20 lo que reafirma cuando se refiere a su incorporación en la ley $\mathrm{N}^{\circ} 19.300$ al señalar que este principio "persigue en lo esencial adoptar medidas anticipatorias que permitan evitar o aminorar las consecuencias adversas para el medio ambiente como producto de la actividad humana..." 21. De hecho, los autores citados sostienen que tanto en estas, como en otras normas ya más específicas, este principio ha permeado en nuestro ordenamiento jurídico, obligando a una visión integrada del Derecho fuera del encasillamiento de la legislación sectorial. Para Ezio Costa, además de los casos ya vistos, "...la existencia del Principio Preventivo como guía se puede observar en la lectura de los artículos que definen el ingreso de un proyecto al SEIA y los instrumentos mediante los cuales es posible obtener una resolución de calificación ambiental..." "22 refiriéndose en este plano a las definiciones del artículo $2^{\circ}$, letras i), j), y f), y el artículo $8^{\circ}$, inciso primero, todos de la ley $\mathrm{N}^{\circ} 19.300$.

\section{3) INDEFENSIÓN DE LAS ÁREAS SILVESTRES PROTEGIDAS}

Circunscribir el concepto de labor minera solo a aspectos vinculados a las excavaciones, deja en la indefensión a las áreas silvestres protegidas respecto de actividades que, al no ser propiamente excavaciones y estar vinculadas a la actividad minera -como las mensuras o prospecciones, e incluso delimitación de pertenencias mineras- podrían llevarse a cabo, no considerando siquiera las disposiciones contenidas en los respectivos planes de manejo que son propios de dichas unidades de protección ${ }^{23}$.

20 Guzmán Rosen, Rodrigo (2012) Derecho Ambiental Chileno. Santiago. Editorial Planeta Sostenible, 268 pp.

21 Guzmán Rosen (2012) pp. 89-90.

22 Costa, Ezio (2013) "La Prevención como principio del Sistema de Evaluación de Impacto Ambiental en Chile”. Justicia Ambiental. Número 5, diciembre 2013. pp. 201-217, p. 204.

23 Estos instrumentos, definidos por la Corporación Nacional Forestal para cada una de las Áreas Silvestres Protegidas (A.S.P.) creadas y confiadas por el Estado a su tuición y administración, contienen las normas que regulan el uso y actividades permitidas en las diversas zonas en que se encuentran sectorizadas. Así, los planes de manejo han sido definidos como "...un instrumento de gestión, que se fundamenta en un proceso de planificación, y que comprende aspectos técnicos, normativos y orientadores destinados a garantizar la conservación de un área protegida, a través del ordenamiento del uso de su espacio". Concepto de Eduardo Núñez en: Nuñez, Eduardo, et al. (2008) Método para la planificación del manejo de Áreas Silvestres Protegidas. Santiago: Corporación Nacional Forestal, 135 pp., p. 19.

En documentos de la UICN se han recopilado otras definiciones que apuntan a un tronco común, tales como las siguientes:

- "Los planes de ordenación y manejo de los parques nacionales y monumentos naturales son el instrumento fundamental para la gestión y la conservación de los mismos, y contendrán en general las directrices, lineamientos y politicas para la administración del área, modalidades de ma- 
La primera esfera de protección de estas áreas, amén de lo que se contempla en la Convención de Washington al definirlas, la encontramos en el reglamento del Sistema de Evaluación de Impacto Ambiental, contenido en el Decreto Supremo N40, de 30 de octubre de 2012, del Ministerio del Medio Ambiente. En este cuerpo normativo, nos encontramos con los artículos 121 y 122, que contienen los permisos ambientales sectoriales (PAS) para ejecutar labores mineras en lugares declarados parques nacionales, reservas nacionales o monumentos naturales (PAS 121) y para ejecutar labores mineras en covaderas o en lugares que hayan sido declarados de interés histórico o científico (PAS 122). En ellos, se establecen los requisitos que deben cumplir los titulares para llevar a cabo estas labores, sin tener aún una definición precisa de ellas. El artículo 121 del reglamento señala: “...El permiso para ejecutar labores mineras en lugares declarados parques nacionales, reservas nacionales o monumentos naturales expresamente para efectos mineros (...) será el establecido en el artículo 17 $N^{\circ} 2^{\circ}$ de la Ley $N^{\circ} 18.248$, Código de Minería”. Por su parte, el artículo

nejo, asignación de usos y actividades permitidos..." (Venezuela, Decreto 276 del 9 de junio de 1989).

- "El plan de manejo conduce y controla el manejo de los recursos protegidos, los usos del área y el desarrollo de los servicios requeridos para mantener el manejo y el uso señalados. Un aspecto central del plan es la especificación de objetivos y metas mensurables que guíen el manejo del área". (UICN, 1990).

- "Los planes de manejo son documentos que orientan el uso y control de los recursos de las áreas naturales protegidas". (Ledec, 1992).

- "El plan de manejo es un instrumento dinámico, viable, práctico y realista, que, fundamentado en un proceso de planificación ecológica, plasma en un documento técnico y normativo las directrices generales de conservación, ordenación y usos del espacio natural para constituirse en el instrumento rector para la ordenación territorial, gestión y desarrollo de las áreas protegidas". (Gabaldón, 1997).

- "El plan de manejo es un instrumento básico de planificación, técnico, regulador y propositivo, para la gestión de un área protegida." (Seminario-Taller Cochabamba, 1998).

- "...el plan de manejo puede ser definido como el documento técnico directriz de planificación, referido a la totalidad del área que se desea proteger, que contiene los antecedentes esenciales, objetivos de manejo, zonificación, y programas especificos de manejo, en los que se incluirán el detalle de sus actividades, normas y requerimientos para alcanzar los objetivos esperados". (Oltremari y Thelen, 1999).

- "El plan de manejo es un documento técnico mediante el cual, con fundamento en los objetivos generales de un área protegida, se establece su zonificación y las normas que deben presidir el uso del área y el manejo de los recursos naturales, inclusive la implantación de las estructuras fisicas necesarias para la gestión del área". (Brasil, Ley 9985 del 18 de julio de 2000).

- "El plan de manejo es una herramienta de apoyo a la gerencia de un área protegida que establece las politicas, objetivos, normas, directrices, usos posibles, acciones y estrategias a seguir, definidas a base de un análisis tecno-politico de los recursos, categoría de manejo, potencialidades y problemática, con la participación de los distintos actores involucrados y donde se concilian la conservación y el desarrollo de acuerdo a la capacidad de los recursos". (ANAM, 2000).

En: Amend, Stepan, et al. (2002) Planes de manejo - Conceptos y propuestas. En: Parques nacionales y Conservación Ambiental, Número 10, Panamá. UICN - GTZ, 110 pp., p. 35. Disponible en: https://portals.iucn.org/library/sites/library/files/documents/2003-046-Es. pdf [fecha de visita: 26 de mayo de 2014]. 
122, respecto a covaderas y zonas de interés histórico o científico establece: "...El permiso para ejecutar labores mineras en covaderas o en lugares que hayan sido declarados de interés histórico o científico expresamente para efectos mineros (...) será el establecido en el artículo $17 N^{\circ} 6^{\circ}$, de la Ley $N^{\circ}$ 18.248, Código de Minería...".

Las normas antes citadas dicen relación con los permisos especiales que deben otorgarse en casos de igual naturaleza, y que se encuentran situados en el artículo 17 del Código de Minería. Dicho artículo, dentro de todas las actividades respecto de las cuales se requiere autorización, establece en dos numerales (artículo $17 \mathrm{~N}^{\circ} 2^{\circ}$ y $17 \mathrm{~N}^{\circ} 6^{\circ}$ ) aquellas relativas a la conservación de la naturaleza, refiriéndose en el numeral 2 a los parques nacionales y el numeral 6 a las covaderas y lugares de interés científico para efectos mineros. No obstante, tampoco se define qué es una labor minera, por lo que, si se interpreta en forma restrictiva, habría una serie de actividades que podrían efectuarse en el interior de estos lugares sin precisar de ninguna autorización especial, lo que pone en riesgo la fragilidad de sus ecosistemas, o la belleza paisajística, elementos determinantes para crearlas como unidades de manejo y conservación.

\section{4) DEFINICIÓN AMPLIA DEL CONCEPTO Y FINES DE CONSERVACIÓN PERSEGUIDOS POR EL ESTADO. SU RELACIÓN CON LA NUEVA INSTITUCIONALIDAD AMBIENTAL}

Definir ampliamente este concepto nos permitirá estar en mejor pie, para responder si las actividades preparatorias del cateo minero, o de apoyo a una faena minera, deben ser autorizadas previamente por el Estado a través de la institucionalidad ambiental existente, o deben considerarse al margen de aquello al no ser consideradas labor minera. Así, cabe preguntarse lo mismo respecto de las obras menores, o de aquellas no comprendidas en lo que puede considerarse parte de la pertenencia minera; tales como los monolitos destinados a marcar los vértices de una pertenencia, o el punto medio, o el punto de interés de la misma. Otro tanto respecto de los tendidos eléctricos para alimentar la faena, o con los acueductos o mineroductos que sean necesarios, cuando estas obras deban desarrollarse en, o pasar a través de un área silvestre protegida.

Desde el enfoque propuesto por la Corte Suprema, estas actividades debieran estar comprendidas dentro del concepto de labor minera, lo que consecuencialmente va a significar que cualquier actividad que se intente ejecutar dentro de un área silvestre protegida, en virtud del artículo 10 , letra p), y eventualmente del artículo 11 , letra d), ambos de la ley $\mathrm{N}^{\circ}$ 19.300, deberán someterse previamente al Sistema de Evaluación de Impacto Ambiental (SEIA), y contar con las autorizaciones contenidas en los PAS 121 y 122 del Reglamento del SEIA. Esta última es una interpre- 
tación más acorde con los fines del Estado, y son las que, por lo general, se han perseguido cuando se ha creado por vía oficial un Área Silvestre Protegida, según puede extraerse de la lectura de los considerandos de sus respectivos Decretos Supremos de creación.

\section{1) ¿DEFINICIÓN LEGAL O JURISPRUDENCIAL?}

Ante lo previamente comentado, el asunto es de importancia capital. Como ya se dijo, nuestro ordenamiento jurídico no se basa en el Common Law, por ende, salvo excepciones en legislación especial-como ocurre en el Derecho Laboral en cuanto al recurso de unificación de jurisprudencia, por ejemplo-, la jurisprudencia no es vinculante, por lo que sus fallos no son erga omnes, limitándose su aplicación a las causas en que actualmente se pronuncian.

El concepto de labor minera, en aras de los fines del Estado en materia de desarrollo sustentable y protección del entorno, debe definirse con una noción amplia y comprensiva. Ante la importancia que reviste definir este concepto, es recomendable que ello se haga por la vía legal e incluso reglamentaria, con el fin de brindar seguridad jurídica, no solo a la protección del patrimonio ambiental del país, sino que también a los titulares de proyectos, y a todos quienes deseen realizar actividades, como aquellas a las que nos hemos referido, dentro de una ASP. Ellos necesitan conocer de antemano el escenario administrativo al que se enfrentarán, previniendo todo riesgo de que su actividad se vea impedida de llevar a cabo, u obligada a retrotraerse; en caso de que una resolución de la Superintendencia de Medio Ambiente, por ejemplo, le obligue a someterse al SEIA o le sancione con multas cuando, producto de la apreciación discrecional de este último organismo, aplique a dicho concepto una definición amplia que comprenda todas las actividades que esté ejecutando o vaya a ejecutar, y que el titular no hubiera previsto como susceptible de ser evaluada. Complicaciones como esta u otras que puedan suscitarse, pueden evitarse regulando y definiendo en texto expreso qué se entiende por labor minera.

\section{5) UNA PROPUESTA DE DEFINICIÓN}

Para definir el concepto de labor minera, se deberán considerar todos los elementos mencionados anteriormente, integrándolos entre sí. Por otra parte, esta integración debe respetar la visión armónica del ordenamiento jurídico, sin destruir lo ya avanzado, sino que dándole una mirada nueva a los elementos existentes.

Lo primero es partir desde la interpretación exegética que se recomienda hacer por el legislador, de acuerdo a lo establecido en el artículo 20 del Código Civil. Una determinación del sentido natural y obvio de 
la voz labor, la hallamos -como mayoritariamente lo ha señalado la doctrina ${ }^{24}$ - en la Real Academia Española de la Lengua. Así, dentro de estas acepciones, labor, es sinónimo de excavación, que se define a su vez como "acción y efecto de excavar" 25.

Ya hemos señalado que esta visión sectorial del concepto, vinculado a las ciencias de la ingeniería, debe ser integrada ampliamente, desde el deber del Estado de proteger la naturaleza y conservar el patrimonio ambiental; visión que se funda -como ya se dijera en párrafos anterioresen la ubicuidad del Derecho Ambiental. Una visión que integre ambas nociones debe considerar que toda actividad que intervenga el territorio en un área silvestre protegida deba ser previamente autorizada por los órganos competentes, y una vez que se hayan cumplido todos los estándares mínimos que resguarden la conservación y preservación del lugar sometido a protección oficial. De esta manera, es que se hace necesario ampliar el concepto de labor minera más allá que la directa excavación de la tierra.

En cuanto a la localización geográfica del concepto dentro de nuestro ordenamiento jurídico, lo más recomendable es situarlo en el Código de Minería, como un inciso final del artículo 17. Es en este punto en el cual el Código hace referencia al concepto sin definirlo, y situarla en el cuerpo normativo más general en materia extractiva da una señal en cuanto a que, salvo las definiciones que se establezcan en leyes especiales, y en el silencio de ellas, regirá el concepto que se fije en dicho código extractivo.

En estos términos, una primera aproximación a una definición amplia podría ser la siguiente:

"Cuando estas actividades se ejecuten en áreas sometidas bajo protección oficial, se entenderá por "labor minera", toda actividad que se realice en un territorio, y que tenga como objeto la preparación y desarrollo de actividades relacionadas a la exploración y explotación minera, y que no haya sido definida como "faena minera" por las leyes o reglamentos".

\section{1) CUANDO SE EJECUTEN EN ÁREAS SOMETIDAS BAJO PROTECCIÓN OFICIAL}

No es una definición que se busque limitar estas actividades sin distinción alguna. El propósito de establecerla es superior, cual es la protección de estos espacios sensibles que el Estado ha protegido en razón de su belleza escénica, fragilidad o valor arqueológico o histórico, en concordancia con los instrumentos internacionales que han sido suscritos y que se encuentran vigentes, y que en virtud del pacta sunt servanda se debe

\footnotetext{
24 Barcia Lehmann, Rodrigo (2010): Código Civil. Doctrina y Jurisprudencia. Tomo I. Thomson Reuters. Santiago. 857 pp., pp. 48-50.

25 Disponible en : http://lema.rae.es/drae/?val=labor [Fecha de visita: 20 de mayo de 2014].
} 
honrar y cumplir con sus disposiciones. Así, solo busca restringir el concepto cuando se trate de la ejecución de ellas en lugares que, por su sensibilidad, deben permanecer intangibles, o impactados en el menor grado posible; lo que hace necesaria una mayor regulación y análisis previo al otorgamiento del permiso respectivo. De este modo, la determinación de la aplicabilidad del concepto no es arbitraria, sino que obedece al deber del Estado de proteger y conservar los recursos, belleza y biodiversidad de estos lugares, muchos de ellos creados por decretos supremos en cuyos considerandos se ha fundamentado claramente las razones por las cuales era necesaria su protección, y que mientras no se les modifique se encuentran vigentes y se deben respetar por la administración. De esta manera, se brinda coherencia al ordenamiento jurídico, pudiéndose implementar esta definición en total armonía con las disposiciones y principios del Derecho Ambiental norma que debe orientar el actuar de la administración, cuando deben ser protegidos y aprovecharse beneficios y servicios ecosistémicos de manera sustentable.

\section{2) TODA ACTIVIDAD QUE SE REALICE EN UN TERRITORIO}

Conteste con lo ya dicho, este enfoque consagra la amplitud de la noción que se busca. No será saludable para el intérprete, el operador o el destinatario de la norma, entrar en distinciones y especificaciones que confundan su sentido y alcance, transformándola en inaplicable. La misma visión holística y ubicua del Derecho Ambiental, ya explicada en párrafos anteriores, y su estrecha relación con el Derecho Minero, al colisionar entre sí los bienes jurídicos protegidos por ambas disciplinas -actividad minera versus protección del entorno- dentro del ámbito de la sustentabilidad de las operaciones mineras, hace necesario que, especialmente cuando se trate de áreas silvestres protegidas, las actividades que abarque este concepto sean de la amplitud más absoluta, de manera que todas ellas deban ser consultadas y sometidas al régimen de permisos que establece el artículo 17 del Código de Minería y el Reglamento del SEIA.

\section{3) QUE SU OBJETO SEA LA PREPARACIÓN Y EL DESARROLLO DE ACTIVIDADES MINERAS}

Con ello, el propósito es no dejar en la indefensión a los lugares sometidos a protección oficial, entre los que se encuentran las áreas silvestres protegidas del Estado, frente a aquellas actividades que no pueden calificarse propiamente como labores mineras miradas desde el punto de vista sectorial, en estado actual en que se encuentra nuestra legislación. La amplitud de la primera parte de la definición se compensa con la gama de actividades que pueden caer en forma genérica dentro de ellas. No son todas las actividades en forma absoluta, sino aquellas que tengan por objeto 
la preparación y desarrollo de actividades mineras, es decir, prospecciones, demarcaciones, mensuras y otras afines.

En otras palabras, no obstante lo absoluto del término, en la misma definición queda claro que la extensión que abarca se encuentra limitada, primero, por la finalidad que se persigue con las actividades proyectadas $y$, segundo, por el contexto en que se van a ejecutar. De esta forma, la totalidad se refiere a aquellas actividades que tengan por objetivo la preparación y desarrollo de actividades relacionadas a la exploración y explotación minera, es decir, las relacionadas con ejercer las facultades que la ley le concede al dueño de una concesión de exploración o de explotación, y aquellos que sin tener dicha propiedad, deseen catar terrenos ajenos conforme a la ley.

\section{4) QUE NO HAYA SIDO DEFINIDA COMO "FAENA MINERA" POR LAS LEYES O REGLAMENTOS}

La definición de este concepto, se enfoca precisamente en abarcar todas aquellas actividades menores propias de la minería, que no hayan sido definidas en otros cuerpos normativos, precisamente porque respecto de ellas recae la duda que posibilita su ejecución sin que se encuentren sometidas al control de la autoridad competente. Sigue siendo amplia, pero a su vez esta amplitud es de carácter genérico, discriminando y no interfiriendo con las conceptualizaciones ya hechas por el legislador en otros cuerpos normativos, de manera de no generar confusiones.

\section{6) CONSECUENCIAS DE ESTA DEFINICIÓN}

En la práctica, la definición de este concepto va a generar reacciones diversas. Por un lado, dará más tranquilidad a los administradores y a quienes tengan bajo su cuidado los lugares sometidos bajo protección oficial, debido a que las actividades de prospección, mensura y otras que puedan caer en esta definición deberán ser previamente autorizadas en base a lo que dispone el Código de Minería y la Ley $\mathrm{N}^{\circ} 19.300$ y su reglamento, velando así por la protección del lugar y la sustentabilidad de sus recursos y servicios ecosistémicos asociados a él. Por su parte, para su concreción en texto legislativo, esta aspiración deberá sortear un largo y accidentado camino, debido a que el solo hecho de involucrar todas las actividades en el concepto de labor minera implicará un eventual encarecimiento variabilidad en el tiempo de estas tareas, lo que redundará necesariamente en los resultados de los análisis de factibilidad que se hagan en forma previa al desarrollo de un determinado proyecto minero; si dentro de los factores a ponderar se agrega la tramitación de permisos hasta hoy no contemplados. 
Sin embargo, se hace necesario apreciar la problemática desde fuera, para concluir que el propósito que se busca no es limitar arbitrariamente las legítimas facultades nacidas del dominio de una concesión minera de exploración o explotación, sino que la finalidad que se persigue no es otra que cautelar un interés superior, igualmente consagrado en nuestra Constitución, como es la preservación de la naturaleza, manifestado en la intangibilidad y uso sustentable restringido de los lugares sometidos a la protección oficial, y que en la práctica se ha materializado en la creación efectiva de ellos.

\section{CONCLUSIONES}

1. La definición del concepto no es pacífica. Por una parte, existe una visión sectorial, propia de la actividad minera y que circunscribe el concepto a una visión restringida, asociada a las actividades de cavar la tierra, y que se fundamenta en reglas de interpretación legal exegética. Por otra parte, se presenta una visión amplia, sostenida por un sector de la doctrina y la jurisprudencia, que se inclina en favor de la alternativa de ampliar la aplicación de este concepto a todas las actividades vinculadas, e incluso preparatorias del cateo y demarcación de una concesión de exploración. Hasta el momento, no hay una posición definitiva que fije el límite entre lo que debe considerarse faena minera, labor minera, y lo que queda definitivamente excluido de ambos conceptos.

2. El concepto de labor minera debe ser definido en su más amplia expresión y no en su noción restrictiva, como recientemente ha sido interpretado por la administración y por alguna jurisprudencia de nuestros tribunales de alzada. Fundamento de ello son las aproximaciones legales y reglamentarias que solo excluyen de tal concepto aquello que no debe entenderse una faena minera-como ocurre en la ley $\mathrm{N}^{\circ} 20.551-$ y la tendencia a incorporar conceptualmente en ella a todas aquellas actividades vinculadas o tendientes a llevar a cabo -actividades de cateo en lo sucesivo-, y que se ha seguido en la jurisprudencia traída a colación y analizada en párrafos anteriores.

3. La definición restringida y sectorial del concepto, en base a un argumento puramente gramatical, pone en peligro el equilibrio de los lugares sometidos bajo protección oficial, cuando estas actividades no definidas, y que son tendientes a preparar otras propias de la actividad extractiva, se lleven a cabo en dichos lugares, cuyos ecosistemas pueden llegar a afectarse irremediablemente, incluso por la intervención antrópica destinada a preparar la extracción de mineral de su seno, o a habilitar caminos o conexiones de ductos o energía tendientes a abastecer una faena minera proyectada o instalada, de- 
jándolos en una virtual indefensión, ante la ejecución de tareas como estas y otras igualmente necesarias para tales fines.

4. La colisión de intereses entre el aprovechamiento de los recursos naturales en favor del minero y la protección del patrimonio ambiental no es nueva, y ha servido para acuñar y aplicar conceptos tales como aprovechamiento sustentable y servicios ecosistémicos en la minería. Ello es producto de la inserción del Derecho Ambiental y sus disposiciones en las bases y principios del Derecho Minero, toda vez que la actividad que es objeto de regulación de este último impacta en mayor o menor medida en el ambiente, debiendo entonces el minero sujetarse en su actividad a las disposiciones, normas y principios propios del Derecho Ambiental.

5. Definir en forma comprensiva el concepto de labor minera, como se indicó, es una manifestación clara de que el Derecho Ambiental es ubicuo, y trasciende a casi la totalidad de las ramas del Derecho. Por lo demás, la definición propuesta se encuentra acorde con el deber del Estado de Chile de garantizar a todas las personas el derecho a vivir en un medio ambiente libre de contaminación, lo que se encuentra en concordancia con los diversos instrumentos internacionales suscritos por el país en materia de protección del medio ambiente, conservación de la biodiversidad y desarrollo sustentable.

6. Ante la incertidumbre que significa la indefinición de este concepto, y las repercusiones que de ello puede derivarse para los titulares de proyectos, las entidades administradoras de áreas sometidas bajo protección oficial y la comunidad en general que pueda verse afectada; no parece suficiente entregar su precisión a la interpretación doctrinaria o judicial, debido a la no exigibilidad de la primera y al carácter no vinculante de la segunda, más allá de las causas que en cada caso sean sometidas a su conocimiento. En este plano, la solución pasa por definir de modo invariable, ya sea por vía legal o reglamentaria, o ambas, qué debe entenderse por labor minera; haciéndose necesario en este caso legislar sobre el particular. Así, podremos evitar conflictos futuros y consecuencias en nuestro entorno que puedan resultar en daños irreparables, particularmente en nuestros territorios más sensibles.

\section{BIBLIOGRAFÍA CITADA}

- Congreso Nacional (1994). Historia de la Ley $N^{\circ} 19.300$ Bases del Medio Ambiente. Valparaíso: 1226 pp. Disponible en: http:// www.leychile.cl/Consulta/portada_hl?tipo_norma=XX1\&nro_ ley=19.300\&anio=2014. [fecha de visita 14 de mayo de 2014], p. 14. 
- Costa, Ezio. (2013) "La Prevención como principio del Sistema de Evaluación de Impacto Ambiental en Chile". Justicia Ambiental. Número 5, diciembre 2013. pp. 201-217, p. 204.

- Guzmán Rosen, Rodrigo (2012) Derecho Ambiental Chileno. Santiago. Editorial Planeta Sostenible, 268 pp.

- Martin Mateo, Ramón (1995) Manual de Derecho Ambiental. Primera Edición. Madrid: Editorial Trivium, 309 pp.

- Núñez, Eduardo et alii (2008) Método para la planificación del manejo de Áreas Silvestres Protegidas. Santiago: Corporación Nacional Forestal, 135 pp., p. 19.

- Vergara Blanco, Alejandro (1992) "Constitucionalidad de la facultad de catar y cavar en suelo ajeno por quien no es aún concesionario minero". Revista de Derecho de Minas y Aguas. Volumen III. Pp. 193-196. Disponible en: http://vergarablanco.cl/ Publicaciones/VI.\%20Derecho\%20de\%20Mineria/AVB\%20VI\%20 25\%201992\%20MINERIA\%20 constitucionalidad $\% 20$ catar $\% 20$ cavar.PDF [Fecha de visita 15 de mayo de 2014], p. 192.

\section{JURISPRUDENCIA CITADA}

- Corte Suprema. 28 de junio de 2006. Rol N ${ }^{\circ}$ 2095-2004. "Minera Ricardo Resources Inc. S.A. con CODELCO Chile". Disponible en http://suprema.poderjudicial.cl/SITSUPPORWEB/ DownloadFile.do?TIP_Documento=3\&TIP_Archivo=3\&COD_ Opcion $=1 \&$ COD_Corte $=1 \&$ CRR_IdTramite $=255168 \& C R R$ _ IdDocumento=129573 [fecha de visita: 15 de mayo de 2014] p. 12 .

- Corte Suprema. 28 de noviembre de 1997. Rol No 21.230-1993. "Monte Patria 1 al 6". Gaceta Jurídica, No 209, pp. 84-88.

- Corte de Apelaciones de Arica. 31 de diciembre de 2004. Rol No 624-2004. "Compañia Minera Barrick Chile Limitada con Corporación Nacional Forestal". 